\title{
ERRATUM
}

Wenjian WEI, Guoliang DING, Haitao HU, Kaijian WANG

\section{Models of thermodynamic and transport properties of POE VG68 and R410A/POE VG68 mixture}

(C) Higher Education Press and Springer-Verlag 2008

Front. Energy Power Eng. China 2008, 2(2): 227-234

Translated from Journal of Shanghai Jiaotong University, 2007, 41(3): 404-410 [译自: 上海交通大学学报]

should be

Translated from Journal of Refrigeration, 2007, 28(1): 3744 [译自: 制冷学报] 